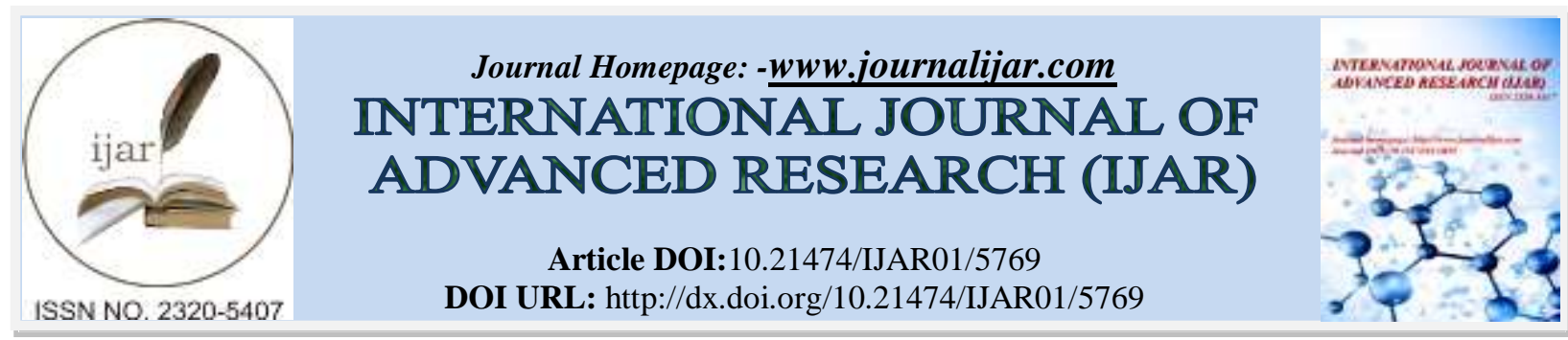

RESEARCH ARTICLE

\title{
EFFECT OF BASIC VEGETATIVE PHASE, PHOTOPERIOD SENSITIVE PHASE AND YIELD PERFORMANCE ON RICE PARENT GENOTYPES AND F1 HYBRIDS IN NEUTRAL DAY LENGTH AND SHORT DAY LENGTH.
}

\section{Zin wai maw ${ }^{1}$ and Irie kenji ${ }^{2}$.}

1. M.Sc. Student of Laboratory of Tropical Crop Science, Department of International Agricultural Development, Tokyo University of Agriculture, Tokyo, Japan.

2. Department of International Agricultural Development, Tokyo University of Agriculture, Tokyo, Japan.

\section{Manuscript Info}

(..........................

Manuscript History

Received: 04 September 2017

Final Accepted: 06 October 2017

Published: November 2017

Key words:-

Parent genotypes, F1 hybrids, Short day, Basic vegetative phase, Photoperiod sensitive phase

\section{Abstract}

Short day conditions accelerated inflorescence initiation, headingor flowering in rice. In rice, the basic vegetative phase and photoperiod sensitive phase have contributed much to the understanding of the flowering behavior. The basic vegetative phase and photoperiod sensitive phase between parent genotypes and F1 hybrids was estimated and yield and yield component traits of parent genotypes and F1 hybrids were studied under short day length and neutral day length condition. Results showed that the basic vegetative phase of F1 hybrids (PSM x IR 24 and PSM x Thaichung 65) was longer than their parents. The photoperiod sensitive phase of PSM x IR 24 was 2 days longer than its male parent IR 24 and it was shorter than its female parent PSM. The photoperiod sensitive phase of PSM x Thaichung 65 was shorter than its female parent and male parents. The grain yield per plant of parent genotypes and F1 hybrids by giving short day treatment was lower than those by giving neutral day length. Our result indicated that short day treatment should be used to get early heading and synchronization for the varieties like Paw San Hmwe (PSM) which is late heading and photoperiod sensitive cultivar and F1 hybrids which are crossed with photoperiod sensitive and insensitive cultivars in breeding program.

Copy Right, IJAR, 2017,. All rights reserved.

\section{Introduction:-}

Rice is one of the world's most important staple crops. Over half of the world's population depends on rice as a staple crop; in Asia, rice supplies 30-80\% of the daily calories consumed (Nareiso and Hossian, 2002). As the world population is increasing year by year, the demand for rice is also increased by $1.13 \%$ per year from 1998 to 2020 . In Myanmar, the present population is 59.78 million in 2010 and is increasing at the rate of 1.15\% per year (MOAI 2014). Among rice varieties; Myanmar local quality rice, Paw San Hmwe is indigenous to Myanmar and is very special, excellent in eating quality, soft texture, and amylase content of about $21 \%$ and with very delightful fragrance. But yield per hectare is relatively low (3.1 -3.6 MT/ha) (Thein, 2011). Therefore, it is urgently required to widen the genetic base and creation of genetic variability through different techniques and needed to increase rice production. Paw San Hmwe is photosensitive and it can only flower under short day condition. Hence, it is needed to create short day condition for PSM to be synchronized and it should be hybridized with other improved varieties. 
In rice, short day conditions accelerated inflorescence initiation, headingor flowering (Morinaga et al., 1955). Short days promoted reproductive development in rice. Short photoperiods of less than 9 or 11 hours were less effective in shortening the vegetative period than longer photoperiods (Asakuma, 1958). The flowering of rice varieties could response to photoperiod (Vergara et.al. 1969). However, the complete information had not been provided on the breeding behavior of different genotypes and F1 hybrids. The vegetative growth period in rice varieties can be divided into two principal phases: basic vegetative phase and photoperiod sensitive phase (Vergara et al. 1965). These two phases have contributed much to the understanding of the flowering behavior in rice (Chang et.al. 1969). The present study was conducted to estimate basic vegetative phase and photoperiod sensitive phase between parent genotypes and F1 hybrids; and to study yield and yield component traits on parent genotypes and F1 hybrids between short day length and neutral day length condition.

\section{Research Method:-}

The experiment was carried out at the greenhouse of Tokyo University of Agriculture from July 2016 to September 2017. Paw San Hmwe (Japonica and photoperiod sensitive variety) and IR 24, Thaichung 65 (Indica and photoperiod insensitive variety) were selected parental line for hybridization. They were grown and cross of Japonica $x$ indica were conducted to obtain F1 hybrids. Two combinations (PSM x IR 24 and PSM x Thaichung 65) were produced after crossing. The resulting F1 hybrids and parent genotypes were evaluated using randomized complete block design with five replications. Short day treatment was given to the seedlings of F1 hybrids and parent genotypes after transplanting for 1 month and $9 \mathrm{hr}$ light and $15 \mathrm{hr}$ dark at 31.C was used. The neutral day length treatment was as in greenhouse condition.

\section{Results AndDiscussion:-}

Estimation of basic vegetative phase and photoperiod sensitive phase on F1 hybrids and their parents between neutral day length and short day length condition

The basic vegetative phase and photoperiod sensitive phase on F1 hybrids and their parents were shown in table 1. Between japonica(photoperiod sensitive) $\mathrm{x}$ indica (photoperiod insensitive) crosses, F1 plants of PSM x IR 24 and PSM x Thaichung 65 showed a longer basic vegetative phase than that of either parent. The basic vegetative phase of PSM x IR 24 (105 days) was longer than that of its female parent, PSM (63 days) and male parent IR 24 (54 days). The basic vegetative phase of PSM x Thaichung 65 was 117 days. For PSM x Thaichung 65, basic vegetative phase was also longer than its two parents, PSM (63 days) and Thaichung 65 (57 days). Chang et.al, 1968 studied that some rice parent genotypes showed basic vegetative phase shorter than their progenies in sensitive and insensitive crosses.In this study, both parents of F1 hybrids showed short basic vegetative phase.

PSM was photoperiod sensitive female parent and its mean photoperiod sensitive phase was 38 days. IR 24 and Thaichung 65 were two photoperiod insensitive parents and their mean basic vegetative phase was 23 and 7 days. Although the photoperiod sensitive phase of PSM x IR 24 (25 days) was 2 days longer than its male parent IR 24, it was shorter than its female parent PSM. The photoperiod sensitive phase of PSM x Thaichung 65 was shorter than its female parent and male parents. Kakizaki, 1938 reported that the photoperiod sensitive phase is the growth stage indicative of the rice plant's sensitivity to photoperiod. The photoperiod sensitive phase of photoperiod insensitive varieties ranges from 0 to 30 days while sensitive cultivars lasts from 31 days or longer.

Evaluation of yield and yield component traits on F1 hybrids and their parents between short day length and neutral day length:-

The comparison of yield and yield component traits on F1 hybrids and parent genotypes were presented in Table 2; and Figure 1, and 2.The mean plant height of every tested parent genotypes in F1 hybrids in short day length was higher than those of tested one in short day length. The reasons for increasing plant height in short day length might be getting required photoperiod for stem elongation and capable of perceiving daylength under certain condition. Wanser, 1922 reported that the stem has apparently specific photoperiodic requirements for stem elongation in the absence of failure in elongation takes place probably.

The mean tiller number of each tested parent genotypes and F1 hybrids in neutral day length was higher than those of short day length. The main culm might be inducted florally and it grew into large tillers in tillers of all tested parent genotypes and F1 hybrids under short day length conditions. The tiller production has been reduced in all tested genotypes including F1 hybrids due to might be prolonged short day treatment until the heading time. Misra, 1954 found that in short day treatment, the average number of tillers and leaves has been very much reduced and the low level is maintained throughout the life period of the plant. 
The days to heading of all tested genotypes and F1 hybrids in short day length was earlier than those in neutral day length. Roberts and Carpenter, 1962 and Sakamoto, 1968 reported that short day treatments of seedlings accelerated heading. Xing- You Gu.et.al, 2004 observed that 9 hour short day treatment reduced flowering time for parents and F1 hybrids compared to neutral day length condition.

The number of panicle per hill between F1 hybrids and their parents in neutral day length and short day length condition were different. PSM x IR 24 did not different between neutral day length and short day length but the no. of panicle per hill of PSM, IR 24, Thaichung 65 and PSM x Thaichung 65 in short day condition was lower than those of neutral day condition. According to the data, it was found that no. of panicle per hill of parent genotypes and F1 hybrid was reduced by giving short day treatment (9hour light and 15 hour dark).Misra, 1954 reported that short day treatment has significantly reduced the number of panicles per plant. Misra and Khan, 1972 found that short day photoperiod markedly reduced the panicle number than neutral day photoperiod.

The panicle length of IR 24 in short day length was shorter than that in neutral day length. But the panicle length of PSM, Thaichung 65, PSM x IR 24 and PSM x Thaichung 65 in short day condition was longer than those of neutral day condition. According to the data, it was found that panicle length of parent genotypes and F1 hybrid was increased by giving short day short day treatment (9hour light and 15 hour dark).Gadahar, 1953 reported that the average panicle length for different treatment is slightly increased in some rice varieties by short day exposure.

The panicle weight of Thaichung 65 in short day length was higher than that in neutral day length. But the panicle weight of PSM, IR 24, PSM x IR 24 and PSM x Thaichung 65 in short day condition was lower than those of neutral day condition. In this study, it was suggested that panicle weight of parent genotypes and F1 hybrid was reduced by giving short day treatment (9hour light and 15 hour dark). Misra and Khan, 1972 reported that short day photoperiod markedly decreased the panicle weight in each variety. Yoshii, 1926 observed that if short day treatment applied to later heading varieties of rice, panicle weight was increased.

The no. of grain per panicle of PSM, Thaichung 65 and PSM x Thaichung 65 in neutral day length was lower than those of short day length. But IR 24 and PSM x IR24 in neutral day length were higher than in short day length in no. of grain per panicle. The reason for decrease in no. of grain per panicle is due to decreasing panicle length in neutral day length. Misra (1954) studied that there is difference in the number of grains per panicle between the plants in neutral day treatment and the plants received short day treatment.

1000 grain weight in F1 hybrids and their parents between neutral day length and short day length condition were not different. Beachell (1943) observed 1000 grain weight was changed neither the influence of short day treatment nor neutral day treatment.

The filled grain (\%) of parent genotypes and F1 hybrid in short day length was lower than that of neutral day length. According to the data, it was found that filled grain \% of all parent genotypes and F1 hybrids at short day length was reduced by giving short day photoperiod. The reason for decrease in filled grain \% is due to increasing sterile grain and reduction number of panicle per plant. Similar reported that the significant reduce in filled grain is due to reduction in the vegetative growth of short day treated plants result in low assimilation and reduction in the number of panicles per plant and the size of the panicles which are much influenced by the length of the vegetative growth period (Misra, 1962).

The grain yield per plant of all parent genotypes and F1 hybrids in neutral day length was higher than those in short day length. In this study, it was found that the grain yield per plant in short day length was adversely affected by giving short day photoperiod. Misra, 1962 reported that the low of yield might be due to partial sterility induced by the short day treatment. According to the result of Misra and Khan (1972), short day photoperiod adversely affected the grain yield irrespective of the month of sowing. The present study showed that the grain yield per plant in neutral day length was increased than the short day length due to the longer period for assimilation, vegetative growth and ripening period. Similar reported that the significant increase in grain yield in the neutral period is due to the longer period for assisimilation and vegetative growth (Misra, 1962). 
Table 1:-Basic vegetative phase and photoperiod sensitive phase on F1 hybrids and parents between neutral day length and short day length

\begin{tabular}{|c|c|c|c|c|}
\hline & \multicolumn{2}{|l|}{ Days to heading } & \multirow{2}{*}{$\begin{array}{l}\text { Basic vegetative } \\
\text { phase (1) }\end{array}$} & \multirow{2}{*}{$\begin{array}{l}\text { Photoperiod- sensitive } \\
\text { phase (2) }\end{array}$} \\
\hline & $\begin{array}{l}\text { SDL } \\
\text { (9hour photoperiod) }\end{array}$ & NDL & & \\
\hline PSM & 98 & 135 & 63 & 38 \\
\hline IR 24 & 89 & 111 & 54 & 23 \\
\hline Thaichung 65 & 92 & 98 & 57 & 7 \\
\hline PSM x IR 24 & 140 & 164 & 105 & 25 \\
\hline PSM x Thaichung65 & 152 & 153 & 117 & 1 \\
\hline
\end{tabular}

1: Minimum growth duration minus 35 days.

2: Longest growth duration at neutral day length (NDL) minus shortest growth duration at short day length (SDL) concluded in this study.
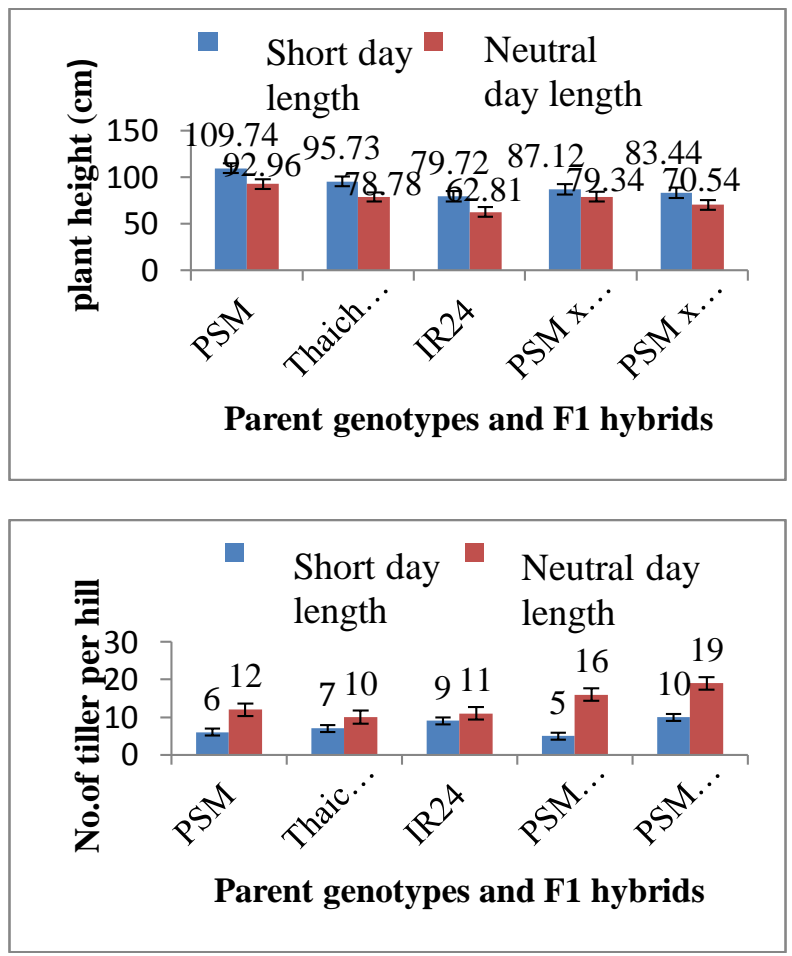

Figure 1:-Plant height and no. of tiller per hill on F1 hybrids and their parents affected by neutral day length and short day lenght

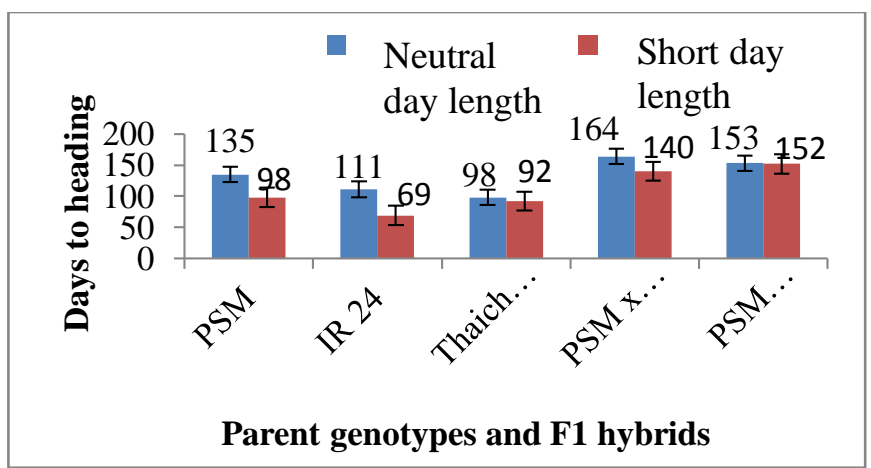




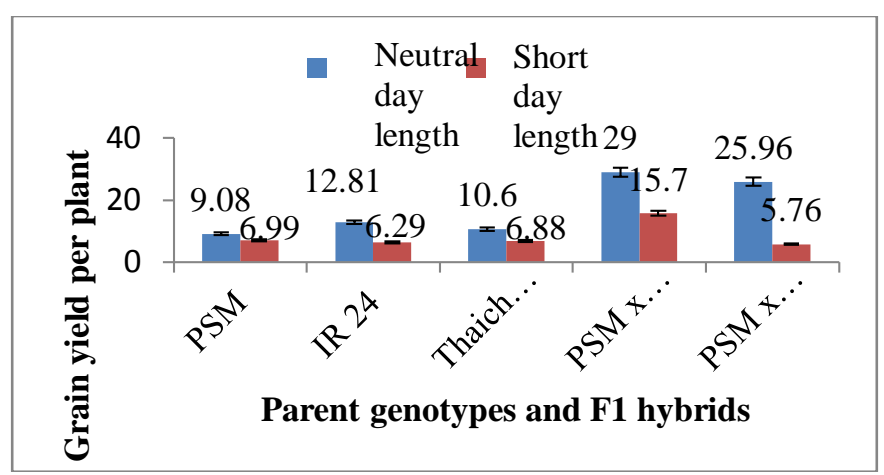

Figure 2:-The days to heading and grain yield per plant on F1 hybrids and their parents affected by neutral day length and short day length

Table 2:-Yield Component traits on parent genotypes and F1 hybrids in short day length and neutral day length

\begin{tabular}{|c|c|c|c|c|c|c|}
\hline \multirow[t]{2}{*}{ Genotype } & \multicolumn{2}{|c|}{ No. of panicle per hill } & \multicolumn{2}{|c|}{ Panicle Length } & \multicolumn{2}{|c|}{ Panicle weight } \\
\hline & $\begin{array}{l}\text { NDL } \\
(\text { Mean } \pm \text { SE) }\end{array}$ & $\begin{array}{l}\text { SDL } \\
(\text { Mean } \pm \text { SE })\end{array}$ & $\begin{array}{l}\text { NDL } \\
(\text { Mean } \pm \text { SE) }\end{array}$ & $\begin{array}{l}\text { SDL } \\
(\text { Mean } \pm \text { SE) }\end{array}$ & $\begin{array}{l}\text { NDL } \\
(\text { Mean } \pm \text { SE) }\end{array}$ & $\begin{array}{l}\text { SDL } \\
(\text { Mean } \pm \text { SE })\end{array}$ \\
\hline PSM & $9 \pm 0.81 \mathrm{c}$ & $8 \pm 0.71 b$ & $22.82 \pm 0.67 a$ & $23.71 \pm 0.65 \mathrm{ab}$ & $1.22 \pm 0.02 b$ & $1.15 \pm 0.08 b c$ \\
\hline IR 24 & $7 \pm 0.58 \mathrm{c}$ & $6 \pm 0.68 b c$ & $22.58 \pm 0.33 a$ & $19.95 \pm 0.48 \mathrm{~d}$ & $1.70 \pm 0.04 \mathrm{ab}$ & $1.53 \pm 0.19 \mathrm{ab}$ \\
\hline Thaichung 65 & $7 \pm 0.24 c$ & $4 \pm 0.37 c$ & $19.94 \pm 0.24 b$ & $22.45 \pm 0.61 b c$ & $1.60 \pm 0.04 \mathrm{ab}$ & $1.97 \pm 0.09 \mathrm{a}$ \\
\hline PSMx IR 24 & $28 \pm 0.58 \mathrm{a}$ & $28 \pm 1.11 \mathrm{a}$ & $18.84 \pm 0.38 b$ & $20.98 \pm 0.63 \mathrm{~cd}$ & $1.96 \pm 0.08 \mathrm{ab}$ & $0.91 \pm 0.01 \mathrm{c}$ \\
\hline $\begin{array}{l}\text { PSM x } \\
\text { Thaichung65 }\end{array}$ & $18 \pm 0.89 b$ & $5 \pm 0.56 c$ & $18.71 \pm 0.37 b$ & $25.95 \pm 0.24 a$ & $2.04 \pm 0.23 \mathrm{a}$ & $1.69 \pm 0.12 \mathrm{a}$ \\
\hline Pr>F & $<0.0001$ & $<0.0001$ & $<0.0001$ & $<0.0001$ & $<0.0001$ & $<0.0001$ \\
\hline CV\% & 10.56 & 16.24 & 4.56 & 18.02 & 15.2 & 5.4 \\
\hline
\end{tabular}

\begin{tabular}{|c|c|c|c|c|c|c|}
\hline \multirow[t]{2}{*}{ Genotype } & \multicolumn{2}{|c|}{$\begin{array}{l}\text { No. of grain per } \\
\text { panicle }\end{array}$} & \multicolumn{2}{|l|}{$\begin{array}{l}1000 \text { grain } \\
\text { weight }\end{array}$} & \multicolumn{2}{|c|}{ Filled grain (\%) } \\
\hline & $\begin{array}{l}\text { NDL } \\
(\text { Mean } \pm \text { SE })\end{array}$ & $\begin{array}{l}\text { SDL } \\
(\text { Mean } \pm \text { SE })\end{array}$ & $\begin{array}{l}\text { NDL } \\
(\text { Mean } \pm \text { SE })\end{array}$ & $\begin{array}{l}\text { SDL } \\
(\text { Mean } \pm \text { SE })\end{array}$ & $\begin{array}{l}\text { NDL } \\
(\text { Mean } \pm \text { SE })\end{array}$ & $\begin{array}{l}\text { SDL } \\
(\text { Mean } \pm \text { SE) }\end{array}$ \\
\hline PSM & $68 \pm 2.51 \mathrm{c}$ & $108 \pm 4.23 \mathrm{ab}$ & $28.20 \pm 0.37 \mathrm{~b}$ & $28.44 \pm 0.38 b$ & $65.8 \pm 1.02 \mathrm{~cd}$ & $21.6 \pm 2.44 \mathrm{c}$ \\
\hline IR 24 & $87 \pm 2.26 b$ & $56 \pm 4.50 \mathrm{~d}$ & $29.40 \pm 0.25 b$ & $29.32 \pm 0.32 \mathrm{ab}$ & $75.2 \pm 2.26 \mathrm{~b}$ & $70.6 \pm 2.89 a$ \\
\hline Thaichung 65 & $64 \pm 2.71 c$ & $97 \pm 4.07 b c$ & $31.40 \pm 0.24 \mathrm{a}$ & $31.59 \pm 0.58 \mathrm{a}$ & $87.4 \pm 1.28 \mathrm{a}$ & $43 \pm 2.30 b$ \\
\hline PSMx IR 24 & $116 \pm 2.80 \mathrm{a}$ & $91 \pm 1.22 \mathrm{c}$ & $29.00 \pm 0.54 b$ & $28.80 \pm 0.73 \mathrm{ab}$ & $62.4 \pm 0.68 \mathrm{~d}$ & $7.6 \pm 1.02 \mathrm{~d}$ \\
\hline $\begin{array}{l}\text { PSM x } \\
\text { Thaichung65 }\end{array}$ & $83 \pm 2.87 \mathrm{~b}$ & $113 \pm 1.70 \mathrm{a}$ & $31.80 \pm 0.73 a$ & $30.20 \pm 1.11 \mathrm{ab}$ & $73.0 \pm 2.97 b c$ & $10.4 \pm 1.86 \mathrm{~d}$ \\
\hline Pr $>$ F & $<0.0001$ & $<0.0001$ & $<0.0001$ & $<0.0001$ & $<0.0001$ & $<0.0001$ \\
\hline CV\% & 7.06 & 8.25 & 3.50 & 5.18 & 5.67 & 15.66 \\
\hline
\end{tabular}

Means followed by the same letter are not significantly different at 5\% level by Tukey'sStudentized Range (HSD) test.

$\mathrm{NDL}=$ neutral day length, $\mathrm{SDL}=$ short day length

\section{Conclusion:-}

From the results of this study, it can be concluded that the basic vegetative phase of F1 hybrids (PSM x IR 24 and PSM x Thaichung 65) was longer than their parents. The photoperiod sensitive phase of PSM x IR 24 was 2 days longer than its male parent IR 24 and it was shorter than its female parent PSM. The photoperiod sensitive phase of PSM x Thaichung 65 was shorter than its female parent and male parents. The grain yield per plant of parent genotypes and F1 hybrids in short day length was lower than in neutral day length. On the other hand, the days to heading of parent genotypes and F1 hybrids by giving short day treatment were earlier than those in neutral day treatment. 
In this study, the dividing of two principal phases for vegetative growth phases would yield basic information for hybridization. The short basic vegetative phase might be facilitated the identification of insensitive and early heading genotypes in breeding program. As for rice breeders, short day treatment should be used to get early heading and synchronization for the varieties like Paw San Hmwe (PSM) which is late heading and photoperiod sensitive cultivar and F1 hybrids which are crossed with photoperiod sensitive and insensitive cultivars in breeding program.

\section{References:-}

1. Askuma, S. 1958. Some aspects of photoperiodisms in rice. Proc. Crop. Sci. Soc. Japan, 27: 61-66.

2. Beachell, H.M. 1943. Effect of photoperiod on rice varieties grown in the field. Jour. Agri. Res., 55, 325-340.

3. Chang, T., L. Cheng-Chang and S.B. Vergra. 1968. Component analysis of duration from seeding to heading in rice by the basic vegetative phase and the photoperiod sensitive phase. Euphytica, 18:79-91.

4. Chang. T. T, C. C. Li and B. S. VERGARA, 1969. Component analysis of duration from seedling to heading in rice by the basic vegetative phase and the photoperiod-sensitive phase. Euphytica18 : 79-91.

5. Gadadhar,M., 1953.Photoperiodism in rice: Photoperiodic response of four early varieties of rice of uttar Pradesh, 29-38.

6. Kakizaki, Y. 1938. A comment on growth physiology and yield of rice plants. AgricHortic. 13: 7-14.

7. Misra, G. 1954. Effect of Short Day length on four late winter varieties of rice of Orissa.Trop.Agr. 171- 182.

8. Misra, G. 1962. Effect of photoperiod on sterility of rice. Phyton, 18, 81-85.

9. Misra. G., and P.A. Khan . 1972. Interaction between short photoperiod and the month of sowing in a late winter indica rice. 137-147.

10. MOAI (Ministery of Agricultural and Irrigation). 2014. Myanmar Agriculture in Brief.Ministery of Agriculture and Irrigation, Myanmar.

11. Morinaga, T. 1954.Studies on photoperiodism in rice. Rep. 5th Meet. Work. Party Rice Breed.Tokyo, p . 2134.

12. Nareiso, J., and M. Hossain. 2002. World Rice Statistics. In, (IRRI).

13. Thein, M.S. 2011. Marginal land vs productive land: A case study on cultivating Myanmar local quality rice (Oryza sativa L.) morphotypes. Phetchaburi, Thailand: P148.LDD.

14. Vergara, B. S, T. T. Chang, R. Lilts, 1969. The flowering response of the rice plant to photoperiod. Tech. Bull. int. Rice Res. Inst., Philippines $8: 1-31$.

15. Yoshii, Y. 1926. Some preliminary studies of the influence upon plants of the relative length of day and night. Tohoku Imp. Univ. Sci. Rpts. Ser. 4, Biol., 2 (2), 143-158. 